\title{
Firm export diversification and change in workforce composition
}

\author{
Sarah Guillou ${ }^{1} \cdot$ Tania Treibich $^{1,2,3}$ (D)
}

Published online: 31 July 2019

(c) The Author(s) 2019

\begin{abstract}
The objective of this paper is to show that part of the fixed cost of a firm's trade expansion is due to the acquisition of new internal capabilities (e.g., technology, production processes or skills), which implies a costly change in the firm's internal labor organization. We investigate the relationship between a firm's labor structure, in terms of the relative number of managers, and the scope of its export portfolio, in terms of its product-destination varieties. The empirical analysis is based on a matched employer-employee dataset covering the population of French firms from tradable sectors over the period 2009-2015. Our analysis suggests that market expansion, both through export entry and export diversification, is associated with a change in the firm's workforce composition, namely an increase in the number of managerial layers. These results are generally confirmed with the use of an instrumental variable approach to control for reverse causality. We show how these results are consistent with a simple model, where the complexity of a firm's operations increases with the number of product-destination couples exported and the manager's role is to address the unsolved problems arising from such increased operational complexity.
\end{abstract}

Keywords Export diversification · Managers · Occupations · Employer-employee data

JEL Classification F16 $\cdot$ E24 $\cdot$ C14 $\cdot$ D22

Tania Treibich

t.treibich@maastrichtuniversity.nl

1 OFCE, Sciences-Po, Paris, France

2 School of Business and Economics, Maastricht University, Tongersestraat 53, 6211LM Maastricht, The Netherlands

3 Sant'Anna School of Advanced Studies, Pisa, Italy 


\section{Introduction}

The recent availibity of employer-employee linked datasets has allowed to study the empirical relation between a change in a firm's international status and the distribution of skills in its domestic workforce (Grossman 2013). When a firm starts exporting or expanding its export portfolio, it may hire professional workers to establish new dedicated teams (Bernard and Jensen 1997; Biscourp and Kramarz 2007) or decentralize decision processes to better address the new production, marketing and distribution problems (Marin and Verdier 2014). It has indeed been shown that exporting can be related to a shift in a firm's employment structure toward higher skills (Serti et al. 2010; Iodice and Tomasi 2015). It follows that such an expansion in size and such a change in the overall nature of skills should require an increase in the complexity of the firm's management structure, as theoretically shown by Caliendo and Rossi-Hansberg (2012). However, to our knowledge, the relation between export behaviour and the management structure of the firm has not yet been empirically studied.

In the international economics literature, several theoretical mechanisms explaining why the employees of exporters present higher skills have been introduced. The first hypothesis is that exporters benefit from increasing returns to skills, hence they have a greater incentive to adopt more advanced technologies of production (Yeaple 2005; Helpman et al. 2010; Amiti and Davis 2012) or to produce higher quality products (Verhoogen 2008). Closer to our framework, Caliendo and Rossi-Hansberg (2012) shows that exporters are required to change their internal labor organization to raise their productivity and sustain the trade cost. In their model, firms that start exporting increase the number of layers of management.

Most explanations so far consider the fixed cost of exporting to be external to the firm. Indeed, the literature discusses the country-specific nature of sunk costs, such as the cost of complying with foreign regulations, establishing distribution networks (Moxnes 2010), or achieving high quality standards (Kugler and Verhoogen 2012) and the cost associated with specific cultural and linguistic barriers (Egger and Lassmann 2015). Instead, the objective of this paper is to show that part of the fixed cost of a firm's trade expansion (through either export entry or export diversification) is the acquisition of new internal capabilities (e.g., technology, production processes or skills), which imply a (costly) change in the firm's internal labor organization.

The empirical relation between trade and the skill structure of firms has been studied in different contexts (Bernard and Jensen 1997; Biscourp and Kramarz 2007; Serti et al. 2010; Iodice and Tomasi 2015). Their results indicate that because exporters demand more high-skilled workers, this induces a rise in their labor costs, explaining the wage premium. ${ }^{1}$ Although these studies also investigate the labor characteristics of exporters with respect to non-exporters, their aim is to explain the

\footnotetext{
1 Technological upgrading following trade liberalization has also been documented by Bustos (2011) in the case of Argentina. In turn, Verhoogen (2008), Helpman et al. (2010) and Baumgarten (2013) show that the extension of trade, as a consequence of trade liberalization, for instance, increases wage inequality within industries.
} 
overall differences in wages, skills and productivity. Thus, they do not consider the way in which these different types of workers are organized within the firm, which instead requires detailed information on firms' distribution of occupations and skills, which was recently made available in matched employer-employee datasets, as we use here.

In the literature on multi-product firms, a firm's range of products is determined by both demand and supply elements. Bernard et al. (2010) consider stochastic shocks to firm productivity and to consumer taste, Eckel and Neary (2010) distinguish between the competition and market-size effects, and Mayer et al. (2014) study the effects of competition and the distance of the products from the core competences of the firm. Caselli et al. (2014) follow Eckel and Neary (2010) and Mayer et al. (2014) by considering the distance to the plant's core expertise which defines its productivity level. The important mechanism put forward in this discussion is that a product's distance to the core competences of the firm is assumed to drive its cost. Indeed, for a given knowledge level, the firm reduces its productivity when enlarging its product scope.

We will extend the analysis of export diversification by multi-product firms by considering export varieties instead of products. As in Broda and Weinstein (2006), we define a variety as a product-destination pair. Adding a new product to the export portfolio is either a product innovation; or a product adaptation to the demand; or a product addition to capture new customers. In all cases, adding a new product is a response to demand characteristics, in other words, it is also a response to destination characteristics. A change in the product portfolio therefore has a strong relation with the targeted destination. On the other side, adding a destination requires the adjustment of the product previously sold by the firm. ${ }^{2}$ Note that such adjustment in specifications (or customization through packaging, design, secondary characteristics) may not often lead to a change in the classification of the product. Using export varieties therefore serves the purpose of accounting for the intertwined nature of product- and destination-types of diversification. ${ }^{3}$ Building on the above insights, why would export diversification, i.e., an increase in the number of products and/or destinations, impact a firm's labor organization?

The first part of the answer relates to the concept of complexity of products and destinations. By adding products and/or destinations, the firm is more likely to encounter production, distribution or marketing "problems" that need to be addressed at a higher management level. Reaching a new destination also means facing new administrative rules, prospecting new distribution networks, and fitting new customers' habits. All these issues call for additional competences. In parallel, when

\footnotetext{
2 There are only few cases when the addition of a destination does not imply a change in the product specifications-they concern very homogenous goods.

3 In the trade literature using firm-level data, export diversification is often associated with destination diversification. However in papers having a more macroeconomic focus, export diversification is associated with product diversity as opposed to specialization (see Caselli et al. 2015; Imbs and Wacziarg 2003) and then it refers explicitly to sector/product differentiation. In particular, in Cadot et al. (2011a, b), export diversification is analysed through both dimensions: the product portfolio and the shipping destinations.
} 
a firm adds new products, it also augments the need for adapting both skills and production processes. This is even more true because trade diversification is associated with investing in $R \& D$ to face tougher foreign competition, as shown by Baum et al. (2016). Thus, similar to Mayer et al. (2014), we associate changes in costs to modifications of the product (here, varieties) portfolio, but we assume that the changes depend on the complexity of the modifications, which is a more general assessment than the distance to the core competences of the firm. Second, trade diversification also has a scale dimension: it is costly because the firm has to manage a higher number-a larger scope - of different products and destinations, increasing the diversity of problems that must be addressed. Therefore, both the qualitative and quantitative aspects of trade diversification increase management complexity and should impact the internal labor organization of the firm.

However, building on the insights from Mayer et al. (2014), the impact of trade diversification on the necessity to implement organizational changes within the firm may depend on how much more complex the new problems caused by trade diversification are with respect to the "business-as-usual" activities in the firm. As we show in our model, a trade-off between the motivation to add varieties to gain from economies of scope and the rise in costs due to the organizational changes required to manage such increased complexity of operations may emerge. Therefore, an empirical investigation is required to test the relation between the use of managers and the export diversification behavior of firms.

Our empirical study is based on three French administrative datasets, and it focuses on the relationship between a firm's organization and export activity, exploiting employee-level data to reconstruct the management structure of individual firms. ${ }^{4}$ The records of exporters' individual transactions are used to measure the scope of a firm's export portfolio. Finally, balance sheet data allow us to control for other firm-level characteristics.

We use a range of methods to test the empirical impact of export entry, and export diversification on the probability to add a layer of management through OLS and probit regressions. In a second step, we control for reverse causality by using an instrumental variable approach. Our findings generally point to the fact that firms that are expanding their export portfolio have a higher probability of adding managerial layers. First, we identify the impact of trade entry on the labor organization of a firm, as measured by the likelihood of adding a layer of managerial occupations. We show that export entry has a different impact on the labor organization than does a mere change in size (here, value added growth). Our results support a positive relationship between a firm's trade diversification and the likelihood that it changes its labor organization. We find that firms expanding their export portfolio have a higher probability of adding managerial layers, after controlling for firm growth, and we confirm these results with an instrumental variable approach.

Our work contributes to the literature in two important ways. First, we show that, on average, a higher share of exporters in general, and among them, those with a

\footnotetext{
4 As in Caliendo et al. $(2015,2017)$, we measure the 'management structure' from the occupational layers composing a firm's workforce.
} 
greater number of export product-destination varieties have a management layer, and that this result still holds after controlling for firm size (total sales). We argue that the increasing complexity that comes with greater trade diversification may constitute an important component of the sunk and fixed costs of exporting. This is especially true if large upfront investments are required to restructure a firm's organization and if the cost of maintaining management layers is inelastic to variations in output volume. Second, we show that trade matters for a firm's hierarchical structure, not only because it expands its market size (Caliendo and Rossi-Hansberg 2012; Caliendo et al. 2017) but also because it increases the complexity of a firm's operations. To illustrate this intuition more formally, we present a simple model in which the complexity of a firm's operations depends on the number of product-destination flows generated, and firms can choose to add managers to address this complexity more efficiently. In the model, because the number of managers is less sensitive to the quantity produced than the number of blue-collar workers, it acts as a fixed cost. Third, our work contributes to the growing literature on the importance of managers for firm performance by proposing a reason why managers are important for firm's exporting performance. Since managers' skills are needed for export diversification, larger and more globalized firms would hire more managers with higher skills. Our results support those by Bender et al. (2018), who state that it is the skills of the group of managers which matter most to translate the best management practices into higher firm performance.

The paper is structured as follows. Section 2 presents our rich dataset, which compiles several data sources. Section 3 displays the descriptive statistics, which illustrate our intuition regarding the relation between trade diversification and labor organization. Section 4 outlines a simple theoretical framework of a multiproduct firm, which supports our empirical evidence. Section 5 tests and discusses the results. Section 6 concludes.

\section{Data}

\subsection{Datasets}

Three main sources of data are required. The first one, the 'Déclaration Annuelle de Données Sociales' (DADS), gathers the compulsory information provided by firms each year to the social administration about their employees. Each observation corresponds to a combination of a worker and an establishment, both with a unique identifier. The variables of interest are the workers' gross wage, number of hours worked, type of contract (mainly used for data cleaning purposes) and occupational category (PCS, 'Professions et Catégories Socioprofessionnelles', 2003) at the 4-digit level.

The second dataset gathers balance-sheet and performance variables per firm (FARE). Both DADS and FARE are provided by the French National Institute of Statistics (INSEE) and cover the universality of French firms, with the exceptions of firms with no employees and those belonging to the agricultural sector. The third dataset is provided by the French customs administration (Custom-DGDDI) and 
records all flows of imports and exports by product, destination and firm. It covers the trade of merchandise and reports, at the product-firm level, the quantity (in $\mathrm{kg}$ ), the country of destination, the product category (CN8), and the value of the export flow. This dataset allows us to precisely trace the firms' performance in foreign markets (i.e., their portfolio of exported products, their prices proxied by their unit-values, patterns of entry and exit to/from foreign markets, and variations in exported value over time).

All three datasets can be matched by using the firm identifier (SIREN), forming a longitudinal dataset covering the period 2009-2015. Note that we restrict our analysis to the main tradable sectors, which include manufacturing (NACE rev.2 sectors 10-33, C), Retail (NACE rev.2 sectors 45-47, G) and ICT services (NACE rev.2 sectors $58-63, \mathrm{~J})$. This is driven first by the use of tradable goods statistics instead of services and because only focusing on manufacturing would exclude numerous firms that export goods even though they belong to the services sector. Moreover, the theoretical mechanisms on which we build relate to the firm's need to reorganize production when facing ability constraints (see Caliendo and Rossi-Hansberg 2012; Caliendo et al. 2015), which is not solely bound to manufacturing firms. Productdiversification can be related to technological adjustments. If that were the only focus, the manufacturing sector would seem like the obvious one to study, because what manufacturing firms sell (i.e. export) is what they produce, so their product portfolio is directly related to their internal capabilities. This is also the case of ICT firms, which produce software for instance. When it comes to destination-diversification however, the picture is less clear-cut. Also retail firms have to deal with the complexity of selling to markets with different legislation, languages, and consumer preferences. Such type of diversification must therefore play a role in influencing their workforce composition changes. In Mayer et al. (2014), the empirical analysis attached to the model is restricted to manufacturing exports in order to "ensure that firms take part in the production of the goods they export". Note however that their variable of interest is productivity, which is much more difficult to measure accurately in services sectors. ${ }^{5}$ We successively use two samples of firm-level data, depending on the object at hand. When studying the decision to enter into exporting and its consequence on the labor organization of the firm, we require firms to be present both in the FARE and DADS datasets (sample 1). Then, when analyzing the export diversification behavior of firms, focusing on exporters only, we require that the firm is in the Customs and DADS datasets, leading to a smaller set of observations (sample 2) and excluding, de facto, smaller exporters that do not report their disaggregated trade flows.

Table 1 describes the population of firms in the two samples. We consider $2,955,088$ observations, corresponding to 682,433 firms and 215,460 exporters (sample 1). Further, we can study the export diversification behavior of nearly half of the latter group $(86,924$ exporters in sample 2). Note that, as discussed in

\footnotetext{
5 Our choice is also driven by empirical considerations: in economies like France (but also the US), manufacturing stands for only $10 \%$ of total GDP. Retailers of manufacturing goods have a large weight in total French export and exporters.
} 
Bernini et al. (2016), only a subset of firms always export, others being intermittent exporters.

\subsection{Construction of variables}

Our aim is to assess the structure of the firms' labor organization based on the available information about the employees' occupational category, following Caliendo et al. (2015). Each employee in the DADS database belongs to a "hierarchical layer" based on the first digit of his occupational category. Consistent with the definition of Caliendo et al. (2015), we identify four possible layers from the bottom of the hierarchy (layer 1) to the top (layer 4). The first layer corresponds to clerks and production workers (blue-collar workers); layer 2 corresponds to intermediate professionals and technicians (supervisors); layer 3 corresponds to executives or senior staff (white collars); and layer 4 is the top management (CEOs, directors). To focus on managerial functions, we then group the layers into "production occupations" (layers 1 and 2 ) and "managerial occupations" (layers 3 and 4). We exclude those firms that do not have the first layer of occupations ( $9 \%$ of observations), i.e., without production or basic operation occupations. ${ }^{6}$ Starting from the DADS employee database, we construct firm-level variables by aggregating the information over each firm-SIREN. We then merge such variables with the FARE and Customs dataset at the firm level.

We have two sources of information regarding exporters with different sample sizes and variables. The FARE dataset registers the total value of exports for all firms, with no legal obligation. Instead, firms are legally bound to provide the customs institution information about their trade flows (by product and destination) above a specified threshold value. ${ }^{7}$ We define exporting firms as firms that declare export sales in the FARE dataset so we can also include smaller exporters. ${ }^{8}$

\section{Empirics about labor organization and export behavior}

Starting from the model of Caliendo and Rossi-Hansberg (2012) and Caliendo et al. (2015) introduced a large amount of empirical evidence on production hierarchies. Focusing on the case of French manufacturing firms over the period 2002-2007, they find support for the theoretical model by Caliendo and Rossi-Hansberg (2012):

\footnotetext{
${ }^{6}$ In the group of firms we discard, ICT firms are over-represented compared to the retail and manufacturing sectors. In addition, those firms are generally very small, but their workforce is relatively skilled, and their export performance is also quite high given their size.

7 Export sales within the European Union need to be declared only if the yearly firm export sales are above $€ 460,000$ for the years 2011 and 2012, and above $€ 150,000$ before 2011 .

8 Because most French firms entering into exports do it within the EU, and intra-EU trade flows only have to be reported above a threshold of 460,000 euros, we would miss most of the dynamics of export entry if we focused instead on the Customs data. Indeed, we would then identify as an "entrant" a firm which was already exporting within the EU for some years and just happened to pass the threshold of 460,000 euros. For this reason, we prefer using FARE to identify export entry in the first part of the paper.
} 
Table 1 Observations description across samples, after cleaning

\begin{tabular}{|c|c|c|c|c|}
\hline \multirow[t]{2}{*}{ Year } & \multicolumn{3}{|c|}{ DADS and FARE (sample 1) } & \multirow{2}{*}{$\begin{array}{l}\text { Sample } 1 \text { and Cus- } \\
\text { toms (sample 2) } \\
\text { Exporters (customs) }\end{array}$} \\
\hline & All & Non-exporters & Exporters & \\
\hline 2009 & 432,877 & 329,432 & 103,445 & 55,348 \\
\hline 2010 & 428,162 & 323,873 & 104,289 & 56,159 \\
\hline 2011 & 423,055 & 331,118 & 91,937 & 52,596 \\
\hline 2012 & 420,154 & 329,366 & 90,788 & 52,825 \\
\hline 2013 & 416,539 & 326,814 & 89,725 & 52,267 \\
\hline 2014 & 413,626 & 323,971 & 89,755 & 51,694 \\
\hline 2015 & 420,675 & 322,063 & 98,612 & 50,761 \\
\hline Total nb. obs. & $2,955,088$ & $2,286,637$ & 668,451 & 371,650 \\
\hline Total nb. firms & 682,433 & 446,675 & 215,460 & 86,924 \\
\hline \# Firms alw. present & 235,982 & - & - & - \\
\hline \# Firms alw. exporters & - & - & 91,639 & 47,074 \\
\hline
\end{tabular}

Manufacturing, retail and IT sectors, 2009-2015

the important growth events that firms experience are associated with an increase in their number of hierarchical layers. Following a pyramidal firm structure, the growth in the number of employees in the existing layers requires the hierarchy at the firm level to be strengthened, e.g., by assigning new managerial positions.

Although our data come from the same source, we cover a more recent period. After checking that the results by Caliendo et al. (2015) are also validated in our data, we find additional evidence regarding the organizational structure of exporting firms. Our focus is on the exporters' trade diversification in terms of products and destinations and its impact on changes in the organization of their labor force, in particular, by observing the change in the presence and composition of managerial layers relative to production or basic operations ones.

\subsection{Firm characteristics and hierarchical structure}

We describe below how the firms in our sample are distributed according to the structure of their hierarchical layers by aggregating based on the firms' employee characteristics. The presence of a layer within a firm is defined by at least one employee belonging to the corresponding occupational level. We observe the heterogeneity across firms along four dimensions: their total number of layers, the presence of managerial layers, their size category and their export status (exporters representing approximately $25 \%$ of the dataset, see Table 1 ). 
Table 2 Percent of observations by number of layers and presence of managers conditional on size classes, 2009-2015

\begin{tabular}{|c|c|c|c|c|c|}
\hline Size class & {$[1-20[$} & {$[20-50[$} & {$[50-250[$} & {$[250-+[$} & All \\
\hline \multicolumn{6}{|l|}{ All firms } \\
\hline 1-Layer & 49.4 & 10.1 & 1.9 & 0.2 & 51.8 \\
\hline 2-Layers & 31.2 & 21.0 & 8.3 & 2.2 & 24.2 \\
\hline 3-Layers & 17.4 & 48.6 & 52.6 & 47.9 & 18.9 \\
\hline 4-Layers & 2.0 & 20.3 & 37.2 & 47.7 & 5.1 \\
\hline Total & 100 & 100 & 100 & 100 & 100 \\
\hline \multicolumn{6}{|l|}{ Exporting firms } \\
\hline 1-Layer & 29.7 & 2.9 & 0.5 & 0.0 & 27.5 \\
\hline 2-Layers & 38.1 & 13.7 & 3.8 & 0.7 & 26.2 \\
\hline 3-Layers & 26.8 & 54.7 & 52.3 & 48.1 & 32.2 \\
\hline 4-Layers & 5.5 & 28.7 & 43.5 & 51.2 & 14.1 \\
\hline Total & 100 & 100 & 100 & 100 & 100 \\
\hline \multicolumn{6}{|l|}{ All firms } \\
\hline Without managerial occupations & 64.6 & 22.1 & 6.5 & 1.7 & 63.8 \\
\hline With managerial occupations & 35.4 & 77.9 & 93.5 & 98.3 & 36.2 \\
\hline Total & 100 & 100 & 100 & 100 & 100 \\
\hline \multicolumn{6}{|l|}{ Exporting firms } \\
\hline Without managerial occupations & 47.2 & 10.5 & 2.4 & 0.3 & 39.9 \\
\hline With managerial occupations & 52.8 & 89.5 & 97.6 & 99.7 & 60.2 \\
\hline Total & 100 & 100 & 100 & 100 & 100 \\
\hline
\end{tabular}

We observe that if most firms in our sample have only a layer of "blue collars" (1-layer), ${ }^{9} 5 \%$ have a complete set of hierarchical layers (4-layers). Table 2 also shows that the distribution of firms across number of layers differs for exporting firms, i.e., more exporters- $46 \%$ - have 3 or 4 layers, compared to $24 \%$ in the general population. Thus, the hierarchical structure of exporting firms seems to be more complicated than that of non-exporting firms.

Next, we simplify the picture by focusing on two levels only: the "production occupations" (only layer 1 or layers 1 and 2) or "managerial occupations" (layer 3, layer 4 or layers 3 and 4). Thus, instead of counting the number of layers, regardless of the level, we identify firms according to whether white collar occupations are present ("managerial occupation") or not (the bottom part of Table 2). When using such a categorization, the distribution of firms is flipped when comparing exporters (60\% of firms with managerial occupations) to the general population (only 36\%). Not surprisingly, the hierarchical organization of firms is also explained by their size

\footnotetext{
${ }^{9}$ Note that in our cleaned sample, all firms have at least one layer, i.e., the lowest one. Therefore by construction, firms with only one employee have the first layer. If we constrain the sample to the group of firms with at least five employees, we observe that the dynamic of hierarchies (i.e. the share of firms adding or dropping layers pf management) is quite similar.
} 
Table 3 Change in the presence of a layer of managers over the period 2009-2015

\begin{tabular}{|c|c|c|c|}
\hline \multirow[t]{2}{*}{$\Delta$ Managerial occupations } & \multicolumn{3}{|l|}{ Percent } \\
\hline & All firms & Exporters & Non-exporters \\
\hline Dropping: -1 & 5.23 & 6.63 & 4.58 \\
\hline No change: 0 & 90.10 & 87.08 & 91.50 \\
\hline Adding: +1 & 4.67 & 6.29 & 3.92 \\
\hline
\end{tabular}

category; i.e., if almost $100 \%$ of the largest firms have managerial occupations, only $35 \%$ of the smallest firms (53\% of the smallest exporters) do. Note that we can only observe employees who earn a salary, so we miss manager-owners (who do not earn a salary). This is why firms without a layer of managers are mostly small firms in which the owner is the unique manager without being registered in managerial jobs.

In addition to these static characteristics, we are interested in the labor organization dynamics, as we study its relation to the export diversification. How often do firms add or drop a layer of management? Table 3 shows that most firms maintained a stable organizational structure between 2009 and 2014. However, exporters were more likely to change their organizational structure. If we suppose that adding a managerial layer can be associated with firm expansion in general and export expansion in particular, what can explain when a firm eliminates managers? Although this is beyond the scope of this paper, eliminating the managers' layer may be observed in firms that are close to exiting or in a process of rationalizing the group organization to which they belong.

Table 4 displays the firm characteristics that are conditional on the presence of managerial occupations. Not surprisingly, firms with managers are larger, considering different size proxies. They also have a higher probability to export and, conditional on exporting, have a higher export intensity. Additionally, given the wellknown size-wage and export-wage premia, we find a positive correlation between the presence of managers among employees and the mean hourly wage. This is coherent with the work of Caliendo et al. (2015) on hierarchical layers and of Egger et al. (2017) on export premium.

We summarize the first set of statistical results as follows:

Empirical fact 1 (2) The organizational structure of exporting firms is more complex than that of non-exporting firms, as the former are more likely to have managerial occupations.

\subsection{Number of products, destinations and layers}

In a next step, we precisely measure the diversification intensity of exporters, with the aim of linking the cost of diversification to the labor organization of firms. Indeed, two exporting firms with similar overall export sales would differ in their 
Table 4 Mean characteristics of firms by hierarchical structure, 2009-2015

\begin{tabular}{|c|c|c|c|c|c|c|}
\hline \multirow[t]{2}{*}{ \# Layers } & \multicolumn{3}{|c|}{ Firm size proxies } & \multicolumn{2}{|c|}{ Export performance } & \multirow{2}{*}{$\begin{array}{l}\text { Labor charact. } \\
\text { Hourly wage }\end{array}$} \\
\hline & $\begin{array}{l}\text { Nb. employ- } \\
\text { ees }\end{array}$ & Value added & Sales & $\begin{array}{l}\text { Exp. propen- } \\
\text { sity }\end{array}$ & Exp. intensity & \\
\hline $\begin{array}{l}\text { Without } \\
\text { managerial } \\
\text { occup. }\end{array}$ & 5.4 & 152.6 & 639.8 & 0.14 & 0.13 & 11.32 \\
\hline $\begin{array}{l}\text { With manage- } \\
\text { rial occup. }\end{array}$ & 47.7 & $2,213.8$ & $11,035.5$ & 0.38 & 0.16 & 17.26 \\
\hline$t$ test & $* * *$ & $* * *$ & $* * *$ & $* * *$ & $* * *$ & $* * *$ \\
\hline
\end{tabular}

Value added, wages and sales are deflated with sectoral price indexes at the 2-digit level

diversification intensity if they serve a different number of product-destination couples, which we label as varieties. Thus, the number of export varieties delivers information about a firm's trade diversification, regardless of its export intensity. A firm that sells one product (defined at the 8-digit level) to two different destinations exports two varieties. By using export data from the French customs (referring to our sample 2, see Table 1), we track the total number of product-destination couples (i.e., varieties) a firm exports per year. ${ }^{10}$

The number of varieties per firm ranges from 1 to 17,455 , with $50 \%$ of exporters shipping fewer than 7 varieties and $95 \%$ fewer than $164 .{ }^{11}$ To complement the information about the number of varieties, we compute a Herfindahl-Hirschmann Index (HHI) at the firm level to appreciate the extent of the diversity of varieties in terms of exported value. For instance, a firm that exports two varieties such that it splits its export value into two equal shares is more diversified than is a firm that exports $98 \%$ of its sales in variety A and $2 \%$ in variety B. Therefore, we consider that the higher the HHI is, the lower the diversification is. By construction, the HHI ranges between 0 and 1 . The distribution of varieties among population of firms is very much skewed and follows a Pareto-like distribution, in coherence with other evidence about exporters' portfolio in other countries (see for instance, Bernard et al. (2009) for US firms, Wagner (2012) for German firms, and Amador and Opromolla (2013) for Portuguese firms). We then cross the information on export diversification with the labor characteristics of the firm (having a layer of managers). We

\footnotetext{
10 The results presented in this paper are robust when using the firms' total number of exported products or destinations as the diversification measure. The results are available from the authors upon request.

11 The number of products per firm ranges from 1 to 835 , with $50 \%$ of exporters shipping fewer than 4 products and $95 \%$ fewer than 45 . The number of destinations per firm ranges from 1 to 168, with 50\% of exporters shipping to fewer than 4 destinations and $95 \%$ to less fewer 43 destinations. We also group the destinations by geographical area. The geographical areas are Europe, Africa, Asia, North-America, Central and South America, Middle-East, Oceania and Others. The number of areas per firm ranges from 1 to 8 , with $50 \%$ of exporters shipping to fewer than 2 areas and $95 \%$ to fewer than 7 areas.
} 
expect that a larger number of varieties is positively correlated with a demand in complex management. It follows that we should find a positive correlation between the presence of managerial occupations and the number of varieties and a negative correlation with the HHI. We also compute the number of new varieties in year $t$ per firm-which means that it has never been present in the varieties portfolio of the firm the years before $t$ (for the span of years we observe in our dataset). ${ }^{12}$

We consider two levels of disaggregation. Defining the varieties at the 8-digit level means that we define a variety with respect to the finest level of product disaggregation (NC8), while the varieties at the 4-digit level refer to the SH4 disaggregation. If the classification is disaggregated more and has more consecutive identifiers, then the products are close to each other. Thus, a change in an 8-digit product without a change in the first 4 digits is a weaker diversification than if the change occurs at the 4-digit level. Considering two levels of disaggregation allows the impact of the intensity of diversification to be tested. Note that a change at the 2-digit level would imply an even more radical diversification. However, at this level, the diversification is too rare to be studied properly.

Table 5 confirms that a firm with managers is more likely to export more products and/or ship to more destinations. Moreover, the presence of managers is also associated with a higher level of new varieties, on average. As expected, all indicators of diversification are positively correlated with the presence of managers' occupations. Moreover, the HHI in terms of varieties is lower with managers than it is without (recalling that a high HHI value is a signal of weak diversification). This evidence confirms our intuition that a more diversified firm-that splits its production and shipment over several product-destination couples in relatively more equal weights-has a higher need for managers.

The above indicators show that French exports cover a very broad portfolio of varieties. However, how many firms modify their portfolio over time? Only $31.6 \%$ of firms keep their portfolio of varieties unchanged during the 5-year period, while nearly $27 \%$ change more than $50 \%$ of their portfolio (Table 6 ).

As a further step, we group exporting firms by the quartile of number of varieties, controlling for firm size. Indeed, we want to disentangle, to the greatest extent possible, the labor organization patterns due to expansion (as measured by firm size) with respect to the role of management complexity due to trade diversification. Table 7 shows that the share of firms with managerial occupations increases with the quartiles.

The additional statistics lead to formulating the following second empirical fact.

Empirical fact 2 (2) Among exporters, the presence of managerial occupations is positively associated with trade diversification.

${ }^{12}$ A variety is not considered a new one in the year the firm enters the database. 
Table 5 Average export diversification indicators conditional on managerial occupations, 2009-2015

\begin{tabular}{|c|c|c|c|c|c|c|}
\hline & \multicolumn{2}{|c|}{ \# Varieties } & \multicolumn{2}{|c|}{ \# New Varieties } & \multicolumn{2}{|c|}{ HHI varieties } \\
\hline & $\mathrm{NC} 8$ & $\mathrm{SH} 4$ & $\mathrm{NC} 8$ & $\mathrm{SH} 4$ & $\mathrm{NC} 8$ & $\mathrm{SH} 4$ \\
\hline $\begin{array}{l}\text { Without managerial } \\
\text { occupations }\end{array}$ & 9.13 & 6.91 & 3.68 & 2.40 & 0.61 & 0.64 \\
\hline $\begin{array}{l}\text { With managerial } \\
\text { occupations }\end{array}$ & 48.31 & 31.81 & 14.32 & 8.08 & 0.45 & 0.48 \\
\hline$t$ t test & $* * *$ & $* * *$ & $* * *$ & $* * *$ & $* * *$ & $* * *$ \\
\hline
\end{tabular}

Table 6 Changes in the trade portfolios of firms between 2009 and 2015

Table 7 Managers' intensity per quartile of varieties, controlling for firm size, 2009-2015

\begin{tabular}{ll}
\hline$\Delta \#$ Varieties & Percent. of firms \\
\hline$<-75 \%$ & 5.7 \\
]$-50 \%,-75 \%]$ & 7.9 \\
] $0,-50 \%]$ & 18.2 \\
$0 \%$ & 31.6 \\
] $0,50 \%]$ & 10.9 \\
] $50 \%, 100 \%]$ & 10.6 \\
$>100 \%$ & 15.1 \\
\hline
\end{tabular}

\begin{tabular}{lll}
\hline & \multicolumn{2}{c}{ \% Firms with managerial occup. } \\
\cline { 2 - 3 } & NC8 & SH4 \\
\hline Q1 \# varieties & 0.60 & 0.60 \\
Q2 \# varieties & 0.66 & 0.65 \\
Q3 \# varieties & 0.74 & 0.74 \\
Q4 \# varieties & 0.83 & 0.83 \\
Q5 \# varieties & 0.93 & 0.93 \\
\hline
\end{tabular}

Next, we present the theoretical mechanisms that could explain these two empirical facts. We propose a theoretical framework that links the relative number of managers of multiproduct firms with their trade diversification decisions.

\section{Model}

Our aim is to assess the impact of an increase in trade diversification on the labor organization of the firm. The model gives a theoretical understanding of the link between a firm's portfolio of varieties, complexity of operations and a need to augment the number of managers. We define export diversification as the addition of a 
new product-destination couple to the firm portfolio of products and destinations. Export diversification is very close to an increase in export performance but may be different in terms of a rise in the export intensive margin.

Mayer et al. (2014) modeled how a firm's range of exported products is affected by competition across market destinations. They find that firms react to increased competition by focusing on their "core", best-performing products. It supports the idea that the product mix and the destination portfolio of exporters are not independent but coevolve. Moreover, their model implies that foreign competition changes the organization of competences in the firm. We augment the model by Mayer et al. (2014) with the findings of Caliendo and Rossi-Hansberg (2012) on the relation between market expansion and firm reorganization and with those of Ottaviano and Thisse (1999) on the firm's revenue side. Caliendo and Rossi-Hansberg (2012) proposed a model of the organization of knowledge and labor within a firm in response to an exogenous demand for differentiated products. The organization of knowledge and labor involves determining the number of managers needed to solve the problems encountered by the employees. Contrary to Caliendo and Rossi-Hansberg (2012), we model only two layers of employees: workers and managers. Given an exogenous distribution of problems faced by the firm, its productivity level depends on the number of managers it uses and on the managers' skills.

Next, we describe the demand (Sect. 4.1) and the supply sides (Sect. 4.2) of the model. The predictions of our theoretical framework are then tested in our empirical analysis (Sect. 5) below.

\subsection{The demand side}

We model the demand as in Mayer et al. (2014). The utility function of an individual consumer $c$ depends on the consumption of a numeraire good $q_{0}^{c}$ and on the consumption of differentiated products $q_{i}^{c}$ distributed over a continuum $\Omega$, as follows:

$$
U=q_{0}^{c}+\alpha \int_{i \in \Omega} q_{i}^{c} d i-\frac{1}{2} \gamma \int_{i \in \Omega}\left(q_{i}^{c}\right)^{2} d i-\frac{1}{2} \eta\left(\int_{i \in \Omega} q_{i}^{c}\right)^{2} d i
$$

where the demand parameters $\alpha, \gamma$ and $\eta$ are all positive. The larger the value of $\gamma$, the greater the consumers' desire for variety is, and the faster their utility increases when they smooth consumption over varieties $i$ in $\Omega$. The parameter $\eta$ determines the degree to which the aggregate consumption of all varieties reduces the marginal utility from the consumption of individual varieties. This utility function generates the following inverse demand for individual varieties:

$$
p_{i}=\alpha-\gamma q_{i}^{c}-\eta Q^{c}
$$

where $p_{i}$ is the price of variety $i$ and $Q^{c}$ is the consumer's aggregate consumption of all differentiated varieties. By inverting (2), we obtain the following linear demand:

$$
q_{i} \equiv L q_{i}^{c}=\frac{\alpha L}{\eta N+\gamma}-\frac{L}{\gamma} p_{i}+\frac{\eta N}{\eta N+\gamma} \frac{L}{\gamma} \bar{p}
$$


where $q_{i}$ is the aggregate consumption of variety $i$ across $L$ consumers in the market. $N$ is the number of differentiated varieties in that market, and $\bar{p}=\frac{1}{N} \int_{i \in \Omega^{*}} p_{i} d i$ is the average price for differentiated goods. $\Omega^{*}$ is the subset of varieties in the market whose price $p_{i}$ is low enough not to drive demand in Eq. (3) to 0. Note that only the varieties with price $p_{i}<p^{M A X}$, where $p^{M A X} \equiv \frac{1}{\eta N+\gamma}(\gamma \alpha+\eta N \bar{p})$, have positive demands.

\subsection{The supply side}

We model the variety portfolio of a firm as a set of product-destination couples $\Theta=[1, \ldots, \theta]$, where the elements are indexed by a continuous series of integers that increase the cost of producing each variety. By assuming that it is easier for the firm to operate in the domestic market, a firm that sells only on the domestic market has a narrower set of product-destination couples. Instead of supposing that the firm is only exporting and does not produce for the domestic market, we collapse the domestic multi-product firm into a single-product firm. It reflects the assumption that adding products to serve the domestic market represents a lower-level of complexity-upgrade, since the customer market (preferences, competitors, legislation) is already known to the firm. Instead, and in line with previous empirical and theoretical results (Bernard and Jensen 1997, 1999), starting to export requires extra skills and knowledge. ${ }^{13}$

An exporter has at least two product-destination items: one product and two destinations (domestic and foreign). The last element of set $\Theta$ represents the product-destination with the highest production cost for the firm. The same product exported to different markets may have different positions in $\Theta$, reflecting the adjustment of costs to meet destination-specific tastes. ${ }^{14}$ We also include the economies of scope through a fixed cost $G$, which drives the decision on the product range. ${ }^{15}$ More precisely, the product range is the number of varieties the firms offer, $\theta$, which is also the level of diversification and product-complexity of the firm. ${ }^{16}$

\footnotetext{
13 From an empirical perspective, the lack of focus on domestic diversification is driven by the data we have: only export sales can be broken down into products; domestic sales are aggregated. However, we argue that such simplification does not contradict our predictions. Indeed, it may be that (unobserved) domestic diversification leads to workforce changes too, however this does not lead to interpret wrongly a positive impact, if any, of trade diversification on the need for managers.

14 The cost side of this section is based on Mayer et al. (2014) and the findings of Caliendo and RossiHansberg (2012). The revenue side is based on the framework of Ottaviano and Thisse (1999).

15 Irrespective of the demand size, a firm has an incentive to produce more than one product because it spreads the fixed cost $\mathrm{G}$ over differentiated products allowing to serve different customers. The fixed cost $G$ is therefore needed to model economies of scope. $G$ has no other utility in the rest of the model.

16 The model does not explicitly account for the size of the destination market or trade costs, however both aspects are indirectly included. Indeed all varieties are ranked in terms of their complexity (how difficult/costly it is to add such product-destination couple). Therefore trade costs and destination size are reflected in this ranking. A further development of the model could disentangle different dimensions of export-related costs and gains - the purpose of this paper is however to provide an initial account of the general impact of trade diversification on the hierarchical structure of the firm.
} 
We assume that exporters follow a pecking order when adding new product-destination couples to their portfolio: they initially export to 'easier' product-destinations, and they later add more difficult items to their portfolio. ${ }^{17}$ This assumption allows us to relate an exporters' optimal managerial structure to the most difficult product exported $\theta$. In addition to the fixed cost $G$, we model the cost associated with the difficulty of producing additional varieties. Next, we model a representative firm and we drop the exponent $j$ to simplify the presentation. Note, however, that the variables are firm-specific.

Each production possibility is associated with a random level of difficulty. Therefore, the blue-collar worker must solve each problem to deliver one unit of output. The probability that a worker solves the problem is described by the following function:

$$
F(z, \theta)=1-e^{-\left(\frac{1}{\theta}\right) z}
$$

where $z$ is the skill level of each blue-collar worker. If the skill of the firm's worker increases, the probability of encountering an unsolved problem decreases. If there are managers in the firm, the complement of $F($.$) is the probability that the prob-$ lem will be handed over to the manager. If there is no manager, the problem is left unsolved and it determines the firm's constraint of capacity/size. This capacity limit therefore also represents an incentive to hire a manager. Of course, the problem can stay unsolved but it limits the firm's growth. ${ }^{18}$ As the firm extends its export portfolio toward more difficult product-destination items (i.e., a larger $\theta$ ), the last exported item generates more difficult problems to solve. This is reflected by the fact that $F(z, \theta)$ decreases in $\theta$. A greater number of unsolved problems determines a greater number of wasted production possibilities, and a larger marginal cost.

Let's assume that the firm can hire a number of managers $n_{m}$ that are more skilled than workers such that $z_{m}>z$. With an additional organization layer, the problems unsolved by the blue-collar workers can be passed on to at least one manager in each firm, who would use $h$ units of time to solve the problem. Thus $z_{m}$ determines the production constraint at the firm level, as follows:

$$
n_{w} A\left(1-e^{-\left(\frac{1}{\theta}\right) z_{m}}\right)>q
$$

where $A$ is the firm-specific average productivity that is common across all products produced by the firm. More specifically, $A$ is the average number of "production possibilities' generated by a worker of the firm in one unit of time. $q$ is the total

\footnotetext{
17 This assumption is supported by empirical evidence on Mexican multi-product exporters provided by Iacovone and Javorcik (2010).

18 There is a trade-off between the gains and costs of hiring managers, therefore it may be possible-for instance if the wage difference is very high, given by a high parameter $k$ - that the firm may find it optimal to remain "small" (i.e. without managers).
} 
production of the firm. If $z_{m}$ is high for a given number of workers $n_{w}$, then the quantity that can be produced, $q$, is higher. ${ }^{19}$

If the problem costs $h$ units of a manager's time, the firm needs at least $n_{m}$ managers to handle the expected number of problems that cannot be dealt with directly by the workers, as follows:

$$
n_{m}=(h)\left(n_{w}\right) e^{-\left(\frac{1}{\theta}\right) z}
$$

The need for managers to face the unsolved problems, which increases with the number of varieties, is stronger when the firm diversifies its export portfolio. This leads to the following:

Lemma 1 For a given skill of workers $z$, the need for managers increases with the number of varieties produced by the firm.

Moreover, the manager-to-worker ratio then increases with the number of product-destinations $\theta$ and decreases with $z$, as follows:

$$
\begin{aligned}
& \frac{\partial\left(n_{m} / n_{w}\right)}{\partial \theta}=\frac{z}{\theta^{2}}(h) e^{-\left(\frac{1}{\theta}\right) z}>0 \\
& \frac{\partial\left(n_{m} / n_{w}\right)}{\partial z}=\frac{-1}{\theta}(h) e^{-\left(\frac{1}{\theta}\right) z}<0
\end{aligned}
$$

'Difficult' product-destinations generate a greater number of production-distribution problems that are beyond the workers' skills, implying a higher manager-toworker ratio. $^{20}$ This result can be formulated as follows:

Proposition 1 Export entry requires a higher number of managers.

This proposition is in line with our empirical fact number 1 and is supported by the evidence presented in Tables 5 and 7 (left columns) in the previous section.

Proposition 2 Trade diversification (i.e., a higher $\theta$ ) requires a higher number of managers, a necessary condition to add a layer of managers.

This proposition is in line with our empirical fact number 2 and is supported by the evidence presented in Table 5 in the previous section.

\footnotetext{
19 The difference between workers' and managers' skill level $z_{m}$ is necessary to understand that the firm encounters a limit to grow. A firm without managers is constrained in the complexity of its activities. Hiring manager(s) with a higher skill level allows to overcome such a constraint.

${ }^{20}$ Note that this result is independent of the size or scale of the firm for a given $\theta$.
} 
Proposition 3 The number of managers relative to workers increases with the scope of a firm's export portfolio $\theta$ and decreases with the skill level of the workers $z$.

\subsection{The cost function}

Production uses labor as the only variable factor of production. The variable cost function is then written as follows:

$$
C(\theta, A, z)=n_{w} \omega+n_{m} k \omega
$$

where $\omega$ is the unit-cost of labor for workers with skill level $z$. The wages of managers are higher, where $k$ is the cost premium associated with their higher skill level.

The firm chooses the value $n_{w}$ that minimizes its cost, subject to two constraints: (6) and (5). The marginal cost of producing and exporting varieties up to item $\theta$ is then as follows (see the proof in the "Appendix" section):

$$
v(\theta, A, z)=\phi=\frac{\omega}{A\left(1-e^{-\frac{z_{m}}{\theta}}\right)}
$$

In contrast to (4), the relevant skill parameter at the numerator of (5) is the managers' skill level $z_{m}$. This reflects the fact that when workers are assisted by managers, any problem unsolved by the workers can be passed through the organizational structure to the upper layer. It is also important to note that the marginal cost is associated with the total amount of production at the firm level, $q$.

Equation (11) below shows that the marginal cost increases with $\theta$ and decreases with the managers' skill $z_{m}$.

$$
\frac{\partial v(\theta, A, z)}{\partial \theta}=\omega\left(A-A e^{-\frac{z_{m}}{\theta}}\right)^{-2}\left(\frac{z_{m}}{\theta^{2}}\right) A e^{-\frac{z_{m}}{\theta}}>0
$$

\subsection{The optimal production level}

In our setting, domestic producers choose to produce a single variety $(\theta=1)$ because they do not benefit from economies of scope. Then, the profit function of domestic producers is $\pi(A, z)=\frac{L}{4 \gamma}\left\{v_{D}-\frac{\omega}{A\left(1-e^{-\frac{2 m}{\theta}}\right)}\right\}^{2}$. Instead, when $\theta>1$, the firm is no longer a single-variety type. Production requires a fixed entry cost to be paid to enter the foreign market, $G$, regardless of the number of varieties, indicating that firms benefit from economies of scope once they start exporting. Following Ottaviano and Thisse (1999), multi-product firms face an aggregate demand for several varieties, where $q_{i}$ corresponds to the demand for each variety. Thus, firm $j$ is facing $q=\int_{i \in \Theta_{j}} q_{i} d i$, where $\Theta_{j}$ is the set of varieties produced by firm $j$, with $\Theta_{j} \in \Omega^{*}$. Then, $\theta_{j}$ is the number of varieties in this set.

Compared to single-product firms, multi-product firms interact with each other through their decision regarding the scope of their varieties relative to the market 
size. The total number of varieties $\Omega^{*}$ is distributed among $J$ firms facing an identical entry cost $G$ in addition to their labor cost depending on the managers skill as in (9).

The profit function for multi-product firms is then as follows:

$$
\pi(m, A, z)=\int_{i \in \Theta_{j}} p_{i} q_{i} d i-n_{w} \omega-n_{m} \omega k-G
$$

We suppose that $p_{i}$ is given to the firm and that firms choose to produce a certain number of varieties, which determines its market share over $\Omega^{*}$. Here, we do not consider any impact on price because the set of varieties is sufficiently large to prevent any firm, by clustering a subset of varieties, from affecting the average market price.

From (2) and (3), we get the following:

$$
p_{i}=\frac{\alpha \gamma}{\eta N+\gamma}-\frac{\gamma}{L} q_{i}+\frac{\eta N}{\eta N+\gamma} \bar{p}=p_{\max }-\frac{\gamma}{L} q_{i}
$$

Then, introducing (13) into (12) gives:

$$
\begin{gathered}
\pi(\theta, A, z)=\int_{i \in \Theta}\left(p_{\max }-\frac{\gamma}{L} q_{i}\right) q_{i} d i-n_{w} \omega-n_{m} \omega k-G \\
\pi(\theta, A, z)=p_{\max } \int_{i \in \Theta} q_{i} d i-\frac{\gamma}{L} \int_{i \in \Theta} q_{i}^{2} d i-n_{w} \omega-n_{m} \omega k-G
\end{gathered}
$$

Maximizing the profit function relative to $q$, we obtain the optimal quantity $q^{*}$ at the firm level.

$$
q^{*}=\frac{\theta L}{2 \gamma}\left[p_{\max }-\frac{\omega}{A\left(1-e^{-\frac{z_{m}}{\theta}}\right)}\right]
$$

It shows that the firm size increases with $\theta$ and with the manager's skill $z_{m}$. As expected, the size increases with productivity and with the size of the market $L$.

Proposition 4 The optimal size increases with trade diversification. It also increases with the manager's skill $z_{m}$.

The optimal level of $\theta$ is determined by the manager's skill $z_{m}$, which comes from the distribution of managers' skill $Z$ in the market. It creates productivity heterogeneity, which determines a firm's ability to trade-diversify. At the equilibrium, this distribution $Z$ drives the total number of varieties and, finally, the competitiveness of the country and its world market share.

In conclusion, the model provides support to the previous empirical findings and directions for the econometrics. It explains that the labor organization is associated 
with trade diversification because the latter implies that there are additional problems to address. It displays a clear trade-off between the scale effect, which motivates the addition of varieties, and the organizational cost, which implies a higher manager-to-worker ratio. This trade-off is affected by the cost of managers and their skill level relative to workers. Although the dynamics are not directly studied, the model provides insight into the changes in a labor organization in response to the decision to increase trade diversification. Indeed, we expect that the complexity of labor organization and the presence of managers are explained by trade diversification. We also expect that a change in the number of hierarchical layers is associated with a change in trade diversification and, specifically, that the probability of adding a layer of managers increases when firms add new varieties to their portfolios. In the next section, we present some econometric tests of the dynamics suggested by the model.

\section{Explaining the change in the number of managerial layers}

Our preliminary descriptive statistics support the main features described by the model. Exporting firms and firms with higher export diversification have more complex labor organizations. Next, we test the dynamic implications of the model. We infer that a firm that decides to enter foreign markets or augment its number of varieties has to implement organizational changes to face the additional complexity. Hence, the descriptive evidence and the model both suggest that the addition of a layer of managers is positively linked to export entry and diversification.

More precisely, we obtain two testable hypotheses from the model: (1) Export entry (i.e., $\theta$ increases from 0 to a strictly positive value) requires a higher number of managers, which increases the probability of adding a layer of management; (2) a higher number of varieties requires a higher number of managers, which increases the probability of adding a layer of management.

However, the results could be driven by other changes in the firm's characteristics, such as firm size. Therefore, we control for firm size and firm growth to disentangle the organizational changes related to growth versus changes in the trade patterns.

We start by testing the first proposition related to export entry, and then we analyze the relation between trade diversification and the probability of adding a layer of management. In this second part, we also instrument export diversification in order to control for potential reverse causality.

\subsection{Export entry and the addition of a layer of managers}

Export entry can be considered the first level of export diversification, as shown by the model. Indeed, adding a new foreign market to the domestic market is a signal of trade diversification. In what follows, we test whether export entry impacts the probability of adding a layer of managers. The estimation sample comprises only firms that do not have a layer of management in the previous period. The dependent 
variable is a dummy variable that takes a value of one when the firm adds one layer of managers to its organizational structure. Export entry is a dummy variable that takes a value of one in year $t$ if the firm was not an exporter in year $t-1$ but does export in year $t$, and it is zero otherwise. ${ }^{21}$

Thus, this specification allows the identification of whether export entry into foreign markets is a good explanatory variable of the decision to add a layer of managers, controlling for other covariates that could explain this decision.

To disentangle the "pure" growth from the export diversification channel explaining the addition of a layer of managers, we add the log growth of the (deflated) value added to the set of explanatory variables and measure the interaction effect between firm growth and the export entry variable. Additional controls include labor productivity (deflated value added over the number of hours worked), in logs; size (the number of employees), in logs; and the number of occupations (occupational categories defined at the 3-digit level, which can be considered as a measure of idiosyncratic diversification of jobs), in logs. The year and the 2-digit level sector fixed effects are also introduced.

Although the dependent variable is binary, we start by using a simple OLS regression with robust standard errors, clustered at the firm level. We then estimate a probit regression.

The results in Table 8 show a positive and significant impact of export entry on the probability of adding a layer of managers in all our specifications. For the probit estimator, the coefficients displayed in the table correspond to the marginal effect of a change in the explanatory variable on the probability of adding a layer of managers. Hence, entering foreign markets augments the probability of adding a layer of managers by 0.007 percentage points. Value added growth is also associated with an increase in the target probability, and we find a complementarity effect of growing and starting to export, leading to an overall impact of export entry of 0.01 points. If growing alone has a greater impact on the probability, the regression results support the independent role of export.

We have performed several additional tests revealing the robustness of our results to the inclusion of sector $\times$ year fixed effects, accounting for the sector-specific dynamics over time; when limiting the analysis to the manufacturing sector (which is often the case in similar literature, especially the trade literature addressing questions related to firm productivity which is not easy to measure in services); and the exclusion of some of our control variables. ${ }^{22}$

\subsection{Export diversification and the addition of a layer of managers}

We now focus on exporters only (those present in the Customs dataset, i.e. sample 2 ), and we test the explanatory power of export diversification with respect to the

\footnotetext{
21 Note that we use here the large sample, sample 1, as export entry is better identified in the FARE dataset. To be precise, export entry means that the firm reports positive export sales in $t$ and zero export sales in the previous period.

22 Tables reporting these results are available in Guillou and Treibich (2019) in Appendix B.1.
} 
Table 8 Impact of export entry on the probability of adding a layer of management, 2009-2015

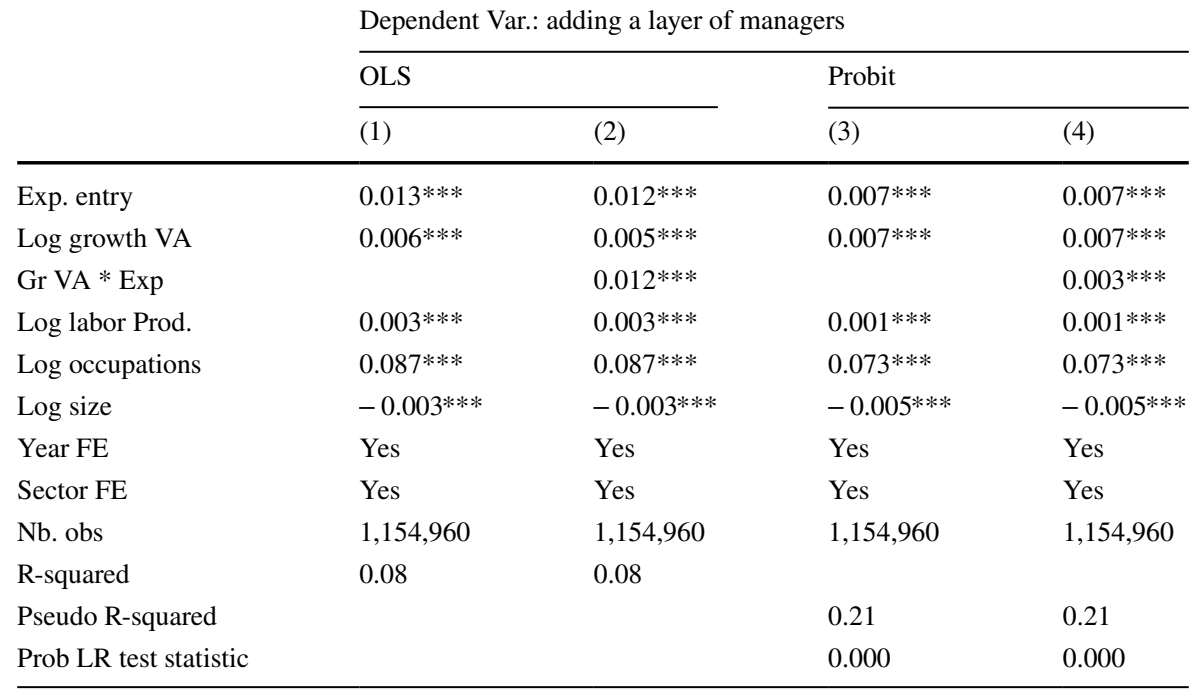

Firms with no layer of management in year $t-1$

OLS standard errors clustered at the firm level

Significance levels: *** $p<1 \%$; ** $p<5 \%$; $p<10 \%$

probability of adding a layer of management. Export diversification is measured in a number of ways. To the standard approach (number of export varieties, concentration of the portfolio) we add a set of variables reflecting a true effort on the part of the firm: the addition of "new-to-the-firm" varieties (i.e. not previously observed in the portfolio of the firm, within our dataset). Indeed, when only observing the number of varieties we may miss some of the dynamics in firms' export portfolio: firms may drop products while adding a new one, or re-export an older one. We count the number of new varieties each year and define: (i) a dummy variable for the presence of new varieties or not; (ii) the share of new varieties relative to the total of varieties a firm exports and (iii) the log number of new varieties. The second and third items reflects whether such changes are expected to have a major weight in the operations of the firm, therefore calling for a change in the workforce composition of the firm.

In Table 9, we compute two sets of probit regressions, alternatively considering varieties at the $\mathrm{NC} 8$ or SH4 disaggregation levels. In each set, we use as dependent variables the number of varieties (col. 1); (ii) a change in the Herfindhal index of varieties (col. 2); the new variety dummy (col. 3); the share of new varieties (col. 4); and the number of new varieties (col. 5).

The diversification decision increases the probability of adding a layer of managers in all our specifications. The specification with the change in the Herfindhal index (col. 2) allows us to evaluate both the evolution in the portfolio of varieties and the extent of such a change. The coefficients are, as expected, negative but weaker compared to the previous measures (and not significant in the case of 4-digit varieties, Panel B). The new varieties dummy (col. 3) allows to evaluate the magnitude of the impact. New varieties augment to probability to add a 
Table 9 Labor organization change and trade diversification: Probit-2009-2015

Dependent Var.: adding a layer of managers

(1)

(2)

(3)

(4)

(5)

Panel A: Probit regressions-8-digit variety

Log \# varieties

$\Delta$ Herfind.

Dummy new var.

Share new var.

Log \# new varieties

Log growth VA

Exp. Int.

Log \# occupations

Log size

Year FE

Sector FE

$\mathrm{Nb}$. obs

Pseudo R-squared

Prob LR test statistic
Log labor Prod.

$0.006^{* * * *}$

$$
-0.011^{* *}
$$

$0.009 * *$

$$
0.026^{* * * *}
$$

$\begin{array}{lllll}0.013 * * * & 0.012 * * * & 0.010 * * * & 0.009 * * * & 0.010 * * * \\ 0.045 * * * & 0.057 * * * & 0.055 * * * & 0.056 * * * & 0.041 * * * * \\ 0.193 * * * & 0.194 * * * & 0.198 * * * & 0.198 * * * & 0.196 * * * \\ 0.007 * * * & 0.008 * * * & 0.009 * * * & 0.009 * * * & 0.007 * * * \\ -0.036 * * * & -0.034 * * * & -0.034 * * * & -0.033 * * * & -0.037 * * * \\ \text { Yes } & \text { Yes } & \text { Yes } & \text { Yes } & \text { Yes } \\ \text { Yes } & \text { Yes } & \text { Yes } & \text { Yes } & \text { Yes } \\ 52,439 & 52,439 & 41,721 & 41,721 & 35,438 \\ 0.16 & 0.16 & 0.16 & 0.16 & 0.15 \\ 0.000 & 0.000 & 0.000 & 0.000 & 0.000\end{array}$

Panel B: Probit regressions-4-digit variety
Log \# varieties

$0.007 * * *$

$\Delta$ Herfind

$-0.007$

Dummy new var.

Share new var.

Log \# new varieties

Log Growth VA

Exp. Int.

Log \# occupations

Log labor Prod.

Log size

$\mathrm{Nb}$. obs

Pseudo R-squared

Prob LR test statistic

$0.012 * * *$

$$
0.027 * * *
$$

$0.009 * * *$

$0.014 * * *$

$\begin{array}{lllll}0.013 * * * & 0.012 * * * & 0.011 * * * & 0.010 * * * & 0.014 * * * \\ 0.045 * * * & 0.057 * * * & 0.053 * * * & 0.056 * * * & 0.057 * * * \\ 0.193 * * * & 0.194 * * * & 0.196 * * * & 0.196 * * * & 0.209 * * * \\ 0.007 * * * & 0.008 * * * & 0.008 * * * & 0.009 * * * & 0.008 * * \\ -0.036 * * * & -0.034 * * * & -0.033 * * * & -0.033 * * * & -0.040 * * * \\ 52,439 & 52,439 & 44,378 & 44,378 & 22,948 \\ 0.16 & 0.16 & 0.16 & 0.16 & 0.15 \\ 0.000 & 0.000 & 0.000 & 0.000 & 0.000\end{array}$

Firms with no layer of management in year $t-1$

Displaying probit average marginal effects

Significance levels: $* * * p<1 \%$; ** $p<5 \%$; $p<10 \%$

layer of management by 1 percentage point when the varieties are observed at the 8-digit level and by 1.2 percentage points when the varieties are observed at the 4-digit level. When considering the impact of the share of a new variety, the impact rises to 2.6 percentage points (2.7 at the 4-digit level). Finally the comparison of the first and last specifications tells us indeed that the number of $n e w$ varieties explains the decision to add a layer of management better than the number of varieties alone. As the regression controls for firm growth and other 
idiosyncratic characteristics, we can conclude that trade diversification has a specific positive impact on the probability of adding managers.

The comparison of the coefficients' magnitude across the two levels of product disaggregation tests one of the hypothesis from the model. In the model, we assume that the higher the complexity implied by diversification is, the higher the likelihood it affects the relative number of managers. Since a new variety is likely to demand more changes in the way the firm operates at the 4-digit level than is a "novelty" that is only observed at the 8-digit level, we expect the impact of the "novelty" on the probability of adding a layer of managers to be higher at the 4-digit level. We confirm this expectation and observe higher marginal effects in columns (1), (3) and (4) but not in column (5). The difference is largest in column (3) (having new varieties vs. none).

As in the previous section, we test whether these results are robust to a range of different specifications. We find that they are confirmed when we use an OLS estimation (with robust standard errors, clustered at the firm level), when including sector $\times$ year fixed effects, and when excluding some of our control variables. However, when limiting our analysis to the manufacturing sector, only the log number of new varieties has a positive impact on the probability to add a management layer in that case. This may indicate that in the manufacturing sector, the addition of a layer of management is better explained by growth processes (sales and value added) than by trade-related constraints. ${ }^{23}$

\subsection{Addressing endogeneity}

In the previous section we document a contemporaneous relation between the decision to enter export markets or expand the number of (new) varieties and the change in the number of hierarchical layers in the firm, i.e. adding managers when there were not before. However it does not test the (causal) direction of the relation. In what follows we discuss the economic mechanisms explaining why export diversification may lead changes in the workforce composition, and the ones which could support the opposite channel. Because none of the directions can be easily discarded, we will use an instrumental variable approach in the following section to test the causal impact of export diversification on the addition of a layer of management.

\subsubsection{The economic mechanisms}

Our empirical framework supposes a relationship going from trade diversification to organizational changes. Any change in a firm's labor organization would be driven by its willingness to move forward to adjust to its competitive or institutional environment, for example a demand shock on foreign markets, or a preferred access to particular markets (for instance through a change in trade costs). We may expect that a firm will not implement organizational changes without strong reasons to do it, because changing the workforce composition and organisation is costly and induces sunk fixed costs.

${ }^{23}$ Tables reporting these results are available in Guillou and Treibich (2019) in Appendix B.2. 
Another rationale behind the impact of exports on the organisation of labour could be a change in the bargaining power of the workforce. For instance, if export access or diversification increases export revenues, workers may ask either for more responsibilities and managerial functions, or for higher wages.

On the other hand, could there be shocks to the labor organisation of the firm which would facilitate export diversification? We can explore a few (specific) cases. The first is the case of a merger or acquisition (M\&A) wich implies a change in the workforce and can lead to a change in the portfolio of varieties. The second is associated with a strong governmental policy reducing the cost of hiring managers (or high-skilled/high-wage workers). If we cannot totally discard the first case for some of the firms, such an external growth event can be captured by the growth in value added. In turn, the second case did not happen in France under the period of study.

Last, we could imagine that a change in trade diversification due to a domestic supply shock (the inability to produce a certain variety, a break in the value chain), would occur simultaneously with a change in employment (caused by the domestic supply shock) such that we would observe a change in the workforce composition together with export diversification, but due to an external unobserved factor.

\subsubsection{Method}

Based on the above discussion, we want to find an exogenous shock to export diversification, which is not associated to the firm's labor organisation decisions. One possible case is a demand shock in export markets. In order to construct our instrument, we build on the one in Mayer et al. (2016), where the authors are interested in the impact of demand shocks in export markets on firm productivity through a reallocation effect: a change in the product portfolio of the firm. More precisely they mainly evaluate the change in the skewness of export sales toward the firm's bestperforming product as a consequence of the growth in imports from non-French firms in the firms' export markets. They document that, as a response to a surge in competition, as proxied by such a demand shock, firms concentrate on their core products (the skewness of their portfolio of products increases).

In order to use their instrument, we face a methodological issue related to the measurement of the (exogenous) export demand shocks. Mayer et al. (2016) compute trade demand shocks at the firm-product-destination level or at the firm-industry-destination level. The same firm can therefore enter the regression for different industry-destination combinations as separate observations, in the same year. Instead, our regressions are executed at the firm level, because firm labor characteristics and labor use cannot be disentangled across products and destinations. We then decide to aggregate the demand shocks faced by a firm over all its product-destination couples. In order to do so, we proceed as follows:

1. We measure total $(\log )$ non-French imports by product-destination in year $t$ : $\log M_{d, t}^{H S 6}$. We use data at the country-HS6 level from the BACI-UN Comtrade 
database. To simplify notation, we write the demand from non-French origins into the product-destination variety $\theta$ as $\log M_{d, t}^{H S 6}=\log M_{t}^{\theta}$.

2. We then compute the average demand faced by each firm $i$ for all product-destination varieties $\theta=1 \ldots \Theta$ in its current product-destination portfolio defined at period $t, \Phi_{i, t}$ as the unweighted mean over $\log M_{t}^{\theta}$ :

$$
D_{i, t}^{\Phi_{i, t}}=\overline{\log M_{t}^{\theta}}=\frac{1}{\Theta} \sum_{\theta \in \Phi_{i, t}} \log M_{t}^{\theta}
$$

For instance, if a firm $i$ exports three varieties in 2009, the international demand $D_{i, t}^{\Phi_{i, t}}$ is the sum of imports from all countries in those markets in 2009 .

3. The demand shock is then the growth of international demand in the markets in which the firm was present in the previous period. So in 2010, the firm considers the markets it knows (those in its portfolio in 2009) and evaluates their growth from 2009 to 2010 . On this basis it may decide to modify its portfolio of varieties in 2010. Following Mayer et al. (2016), we define the trade demand shock as the following change in demand:

$$
\tilde{\Delta} D_{i, t}=\left(D_{i, t}^{\Phi_{i, t-1}}-D_{i, t-1}^{\Phi_{i, t-1}}\right) /\left(.5 D_{i, t}^{\Phi_{i, t-1}}+.5 D_{i, t-1}^{\Phi_{i, t-1}}\right)
$$

We compute this trade shock for each firm-year from 2009 to 2015 . Note that the portfolio structure is adjusted in each year $t$, based on the information in $t-1$. We do so because we want to correlate the change in the trade diversification and the demand shock. By excluding France from the source of imports, we nevertheless keep the demand shock independent from French exporters' own performance.

We then estimate the impact of the firm-specific shock $\tilde{\Delta} D_{i, t}$ on the five proxies of export diversification in the first stage of a 2SLS regression (Eq. 17), where $\operatorname{Exp}=[\log (\#$ var $) ; \Delta H H I ;$ New var; Share new var.; $\log (\#$ new var. $)]$ In the second stage (Eq. 18), the predicted value of the export diversification variable from the first stage is included as a regressor to estimate its impact on the dependent variable Adding:

$$
\begin{gathered}
\operatorname{Exp}_{i, t}=\beta_{0}+\beta_{1} \tilde{\Delta} D_{i, t}+\beta_{2} X_{i, t}+\beta_{3} \sigma_{j}+\beta_{4} \lambda_{t}+\epsilon_{i, t} \\
\operatorname{Adding}_{i, t}=\gamma_{0}+\gamma_{1} \hat{E x p}_{i, t}+\gamma_{2} X_{i, t}+\gamma_{3} \sigma_{j}+\gamma_{4} \lambda_{t}+\mu_{i, t}
\end{gathered}
$$

In both equations, we also include a set of control variables $X_{i, t}$, sector fixed effects $\sigma_{j}$ and time fixed effects $\lambda_{t} . \epsilon_{i, t}$ and $\mu_{i, t}$ are the error terms.

\subsubsection{Results}

The instrumental variable $\tilde{\Delta} D_{i, t}$ appears to be quite symmetric with a median and mean of 0.003 and 0.004 respectively, slightly skewed to the positive side $(-0.006)$. We remove outliers of the variable, identified as the values above 10.21 , which corresponds to the first and 99th percentiles of the distribution. 
The results presented in Table 10, Panel A, show that the first stage is valid and highly significant for three out of the five proxies of export diversification (columns 1, 3 and 5). The instrument is particularly suited for the variables identifying changes at the extensive margin: an increase in the number of varieties, in the number of new varieties and in the occurrence of new varieties. For those variables, a positive demand shock triggers an increase in export diversification. Instead it is not significantly associated with the variables documenting the structure of the portfolio, that is, the share of the new varieties and the change in the concentration of varieties.

The second stage of the 2SLS estimation then shows that when the first stage is significant (columns 1, 3 and 5), export diversification has a positive and significant causal impact on the probability to add a layer a managers. The results are confirmed when measuring export variables at the 4-digit level (Panel B). In addition, they are clearly stronger in Panel B with respect to Panel A, showing that the causal impact of export diversification on workforce composition is affected by the distance (in terms of product characteristics here) between the existing and new varieties.

In both panels $\mathrm{A}$ and $\mathrm{B}$, the Kleibergen-Paap rk statistic (Kleibergen and Paap 2006) leads to reject the hypothesis that the instruments are weak in regressions (1), (3) and (5). ${ }^{24}$

\section{Conclusion}

This study investigates the impact of export expansion (i.e., export entry and export diversification) on the labor structure of firms. Supported by a simple model of a multi-product firm which decides to diversify, we test the hypothesis that firms' workforce composition, and notably their management level, results from the complexity to deal with problems generated by export diversification.

We found that the organizational structure of exporting firms is more complex than that of non-exporting firms, as they present a higher probability to have a layer of management on average.

Our empirical results support the main features described by the model. A firm that decides to enter foreign markets or augment its number of export varieties must implement organizational changes to face the complexity raised by the increase in its scope of varieties. First, we identify the impact of trade entry on the labor organization of a firm, as measured by the likelihood of adding a layer of managerial occupations. We show that export entry has a different impact on the labor organization than does a mere change in size (here, value added growth). Our results support a positive relationship between a firm's trade diversification and the likelihood that it changes its labor organization. We find that firms expanding their export portfolio have a higher probability of adding managerial layers, after controlling for firm growth, and we confirm these results with an instrumental variable approach.

\footnotetext{
24 The $\mathrm{F}$ statistic reported in Table 10 is higher than the critical value provided by Stock and Yogo (2005) for a $10 \%$ threshold.
} 
Table 10 Labor organization change and trade diversification

Dependent Var.: adding a layer of managers

(1)

Panel A: IV Regressions: 8-digit variety

First stage

$\Delta$ Tilde

R-squared $1.588 * * *$

0.025

0.255

0.006

$0.275 * * *$

0.442

0.038

$0.942 * * *$

Second stage

Log \# varieties

$\Delta$ Herfind.

Dummy new var.

Share new var.

Log \# New Varieties

Log growth VA

Exp. Int.

Log \# Occupations

Log labor Prod.

Log size

Year FE

Sector FE

$\mathrm{Nb}$. obs

Wald $\chi^{2}$

Kleibergen-Paap rk Wald F-Stat

$0.079^{* * *}$

4.971

4.971

$$
0.560 * * *
$$

4.018

$\begin{array}{lllll}0.013 * * * & 0.120 & 0.001 & -0.113 & 0.124 * * \\ -0.083^{*} & 0.103 & -0.054 & -0.093 & -0.103 \\ 0.169 * * * & 0.167 * * * & 0.156^{* * *} & 0.058 & 0.171^{* * *} \\ -0.005 & 0.016 & 0.002 & 0.046 & -0.005 \\ -0.046 * * * & 0.001 & -0.031^{* * *} \text { v } 0.023 & -0.051^{* * *} & \\ \text { Yes } & \text { Yes } & \text { Yes } & \text { Yes } & \text { Yes } \\ \text { Yes } & \text { Yes } & \text { Yes } & \text { Yes } & \text { Yes } \\ 50,521 & 50,521 & 40,573 & 40,573 & 34,159 \\ 520,498.46 & 38,154.62 & 249,034.26 & 56,771.27 & 298,799.72 \\ 162.26 & 0.47 & 24.86 & 0.99 & 51.1\end{array}$

Panel B: IV Regressions: 4-digit variety

First stage

$\Delta$ Tilde

R-squared

$\begin{array}{lll}0.886^{* * * *} & 0.003 & 0.209^{* * *} \\ 0.242 & 0.005 & 0.341\end{array}$

0.011

$0.387 * * *$

Second stage

Log \# varieties

$0.141 * *$

$\Delta$ Herfind.

44.092

Dummy new var.

Share new var.

Log \# New Varieties

Log growth VA

Exp. Int.

Log \# occupations

Log labor Prod.

Log size

Year FE

Sector FE

$\mathrm{Nb}$. obs

Wald $\chi^{2}$

Kleibergen-Paap rk Wald F-Stat

$\begin{array}{lll}0.016^{* * *} & 0.911 & 0.002 \\ -0.168^{* *} & 0.386 & -0.089 \\ 0.163 * * * & 0.162 & 0.146^{* * *} \\ -0.014 * & 0.091 & -0.001 \\ -0.062^{* * *} & 0.127 & -0.033^{* * *} \\ \text { Yes } & \text { Yes } & \text { Yes } \\ \text { Yes } & \text { Yes } & \text { Yes } \\ 50,521 & 50,521 & 43,078 \\ 361,321.43 & 556.88 & 215,450.26 \\ 60.36 & 0.01 & 12.95\end{array}$

(5)

0.192
11.743

$\begin{array}{ll} & 0.394 * * \\ -0.311 & 0.001 \\ -0.302 & -0.137 \\ 0.155 & 0.179 * * * \\ 0.091 & -0.013 \\ 0.101 & -0.064 * * \\ \text { Yes } & \text { Yes } \\ \text { Yes } & \text { Yes } \\ 43,078 & 22,113 \\ 20,566.54 & 95,589.50 \\ 0.10 & 10.78\end{array}$

Firms with no layer of management in year $t-1$

Standard errors clustered at firm level 
In the framework of Mayer et al. (2016), holding the firm-product productivity constant, overall firm productivity changes "mechanically" from the reallocation effects (i.e. via a higher weight of the higher-productivity products). We hypothesize that an additional channel is likely to play: we suggest that trade demand shocks may affect firms' labor organisation, which is then associated both to a change in the product portfolio and to a change in the overall productivity of the firm (so, (unobservable) firmproduct productivity would then change too).

Overall, we obtain a body of evidence that supports a positive relation between export diversification and change in labor organization through the addition of layers of management.

One limit of our analysis is that we do not address the narrowing of a firm's varieties portfolio. Dropping a product or a destination could signal the decision to invest abroad instead of exporting. The FDI option and its impact on the skills of the workforce were explored by Laffineur and Mouhoud (2015) using French data. Future research could adapt our current framework to account for such process. Our research agenda also relates to the import activity of the firm, which may have a non-negligible effect on its labor organization.

Acknowledgements This paper has benefited from comments of many seminar and conference participants at DEGIT 2017, ETSG 2015, CAED 2015, the Aarhus International Trade Workshop 2016 and the Maastricht University faculty seminar. We acknowledge financial support from the H2020 Project: 'Innovation-fuelled, Sustainable, Inclusive Growth (ISIGROWTH)' under Grant Agreement 649186.) This work is also supported by a public grant overseen by the French National Research Agency (ANR) as part of the 'Investissements d'avenir' program (reference: ANR-10-EQPX-17, Centre d'accès sécurisé aux données, CASD).

Open Access This article is distributed under the terms of the Creative Commons Attribution 4.0 International License (http://creativecommons.org/licenses/by/4.0/), which permits unrestricted use, distribution, and reproduction in any medium, provided you give appropriate credit to the original author(s) and the source, provide a link to the Creative Commons license, and indicate if changes were made.

\section{Appenidx: Proof of (19)}

Starting from the following cost function:

$$
C(\theta, A, z)=n_{w} \omega+n_{m} k \omega
$$

We minimize the cost function relative to $n_{\omega}$ under two constraints, given by (5) and

(6). The Lagrangian to minimize is then as follows:

$$
\min \{L(\theta, A, z)\}=\min \left\{n_{w} \omega+n_{m} k \omega+\phi\left[q^{j}-A\left(1-e^{-\frac{z_{m}}{\theta}}\right) n_{w}\right]\right\}
$$

Let $n_{m}=1$, then $n_{w}$ is the number of workers per manager. The relation between managers and workers is then as follows:

$$
n_{w}=\frac{1}{h} e^{\left(\frac{1}{\theta}\right) z}
$$

Substituting in (20), we get the following: 


$$
\begin{gathered}
\min \{L(\theta, A, z)\}=\min \left\{n_{w} \omega+k \omega+\phi\left[q-A\left(1-e^{-\frac{z_{m}}{\theta}}\right) \frac{e^{\frac{z}{\theta}}}{h}\right]\right\} \\
\frac{\partial L}{\partial n_{w}}=\omega-\phi A\left(1-e^{-\frac{z_{m}}{\theta}}\right)=0
\end{gathered}
$$

Hence, from this equation, we can extract the value of $\phi$, the marginal cost of production $\left(\frac{\partial L}{\partial q}\right)$, as follows:

$$
v(\theta, A, z)=\phi=\frac{\omega}{A\left(1-e^{-\frac{z_{m}}{\theta}}\right)}
$$

Note that it increases with $\theta$ and decreases with the managers' skill.

\section{References}

Amador, J., \& Opromolla, L. D. (2013). Product and destination mix in export markets. Review of World Economics, 149(1), 23-53.

Amiti, M., \& Davis, D. R. (2012). Trade, firms, and wages: Theory and evidence. The Review of Economic Studies, 79(1), 1-36.

Baum, C. F., Caglayan, M., \& Talavera, O. (2016). R\&D expenditures and geographical sales diversification. Manchester School, 84(1), 201-217.

Baumgarten, D. (2013). Exporters and the rise in wage inequality: Evidence from German linked employer-employee data. Journal of International Economics, 90(1), 201-217.

Bender, S., Bloom, N., Card, D., Van Reenen, J., \& Wolter, S. (2018). Management practices, workforce selection and productivity. Journal of Labor Economics, 36(S1), S371-S409.

Bernard, A. B., \& Jensen, J. B. (1997). Exporters, skill upgrading, and the wage gap. Journal of International Economics, 42(1-2), 3-31.

Bernard, A. B., \& Jensen, J. B. (1999). Exceptional exporter performance: Cause, effect, or both? Journal of International Economics, 47(1), 1-25.

Bernard, A. B., Jensen, J. B., \& Schott, P. K. (2009). Importers, exporters and multinationals: A portrait of firms in the U.S. that trade goods. In Producer dynamics: new evidence from micro data, NBER Chapters (pp. 513-552). National Bureau of Economic Research, Inc. https://ideas.repec.org/h/nbr/ nberch/0500.html. Accessed 1 June 2019.

Bernard, A. B., Redding, S. J., \& Schott, P. K. (2010). Multiple-product firms and product switching. American Economic Review, 100(1), 70-97.

Bernini, M., Du, J., \& Love, J. H. (2016). Explaining intermittent exporting: Exit and conditional re-entry in export markets. Journal of International Business Studies, 47(9), 1058-1076.

Biscourp, P., \& Kramarz, F. (2007). Employment, skill structure and international trade: Firm-level evidence for France. Journal of International Economics, 72(1), 22-51.

Broda, C., \& Weinstein, D. E. (2006). Globalization and the gains from variety. The Quarterly Journal of Economics, 121(2), 541-585.

Bustos, P. (2011). Trade liberalization, exports, and technology upgrading: Evidence on the impact of MERCOSUR on Argentinian firms. The Americal Economic Review, 101(1), 304-40.

Cadot, O., Carrere, C., \& Strauss-Kahn, V. (2011a). Export diversification: What's behind the hump? The Review of Economics and Statistics, 93(2), 590-605.

Cadot, O., Carrere, C., \& Strauss-Kahn, V. (2011b). Trade diversification: Drivers and impacts. In M. Jansen, R. Peters, \& J. Salazar-Xirinachs (Eds.), Trade and employment: From myths to facts. Geneva: ILO-EC. 
Caliendo, L., Monte, F., \& Rossi-Hansberg, E. (2015). The anatomy of french production hierarchies. Journal of Political Economy, 123(4), 1393-1467.

Caliendo, L., Monte, F., \& Rossi-Hansberg, E. (2017). Exporting and organizational change. (Working Paper 23630). National Bureau of Economic Research.

Caliendo, L., \& Rossi-Hansberg, E. (2012). The impact of trade on organization and productivity. The Quarterly Journal of Economics, 127(3), 1393-1467.

Caselli, F., Koren, M., Lisicky, M., \& Tenreyro, S. (2015). Diversification through trade. (Working Paper 21498). National Bureau of Economic Research.

Caselli, M., Chatterjee, A., \& Woodland, A. (2014). Multi-product exporters, variable markups and exchange rate fluctuations. (Discussion Papers 2014-15). School of Economics, The University of New South Wales.

Eckel, C., \& Neary, J. P. (2010). Multi-product firms and flexible manufacturing in the global economy. Review of Economic Studies, 77(1), 188-217.

Egger, H., Egger, P., Kreickemeier, U., \& Moser, C. (2017). The exporter wage premium when firms and workers are heterogeneous. (CEPIE Working Paper No. 12/17). Center of Public and International Economics.

Egger, P. H., \& Lassmann, A. (2015). The causal impact of common native language on international trade: Evidence from a spatial regression discontinuity design. The Economic Journal, 125(584), 699-745. https://doi.org/10.1111/ecoj.12253.

Grossman, G. M. (2013). Heterogeneous workers and international trade. Review of World Economics, 149(2), 211-245.

Guillou, S., \& Treibich, T. (2019). Firm export diversification and change in workforce composition. (OFCE Working Paper 09/2019). Sciences Po.

Helpman, E., Itskhoki, O., \& Redding, S. (2010). Inequality and unemployment in a global economy. Econometrica, 78(4), 1239-1283.

Iacovone, L., \& Javorcik, B. S. (2010). Multi-product exporters: Product churning, uncertainty and export discoveries. The Economic Journal, 120(544), 481-499.

Imbs, J., \& Wacziarg, R. (2003). Stages of diversification. American Economic Review, 93(1), 63-86.

Iodice, I., \& Tomasi, C. (2015). Skill upgrading, wage gap and international trade: Firm-level evidence for Italian manufacturing firms. Technical Report 2015/06, Laboratory of Economics and Management (LEM), Sant'Anna School of Advanced Studies, Pisa, Italy.

Kleibergen, F., \& Paap, R. (2006). Generalized reduced rank tests using the singular value decomposition. Journal of Econometrics, 133(1), 97-126.

Kugler, M., \& Verhoogen, E. (2012). Prices, plant size, and product quality. The Review of Economic Studies, 79(1), 307-339.

Laffineur, C., \& Mouhoud, E. M. (2015). The jobs at risk from globalization: The French case. Review of World Economics, 151(3), 477-531. https://doi.org/10.1007/s10290-015-0221-1.

Marin, D., \& Verdier, T. (2014). Corporate hierarchies and international trade: Theory and evidence. Journal of International Economics, 94(2), 295-310.

Mayer, T., Melitz, M. J., \& Ottaviano, G. I. (2014). Market size, competition, and the product mix of exporters. The American Economic Review, 104(2), 495-536.

Mayer, T., Melitz, M. J., \& Ottaviano, G. I. (2016). Product mix and firm productivity responses to trade competition. (Working Paper w22433). National Bureau of Economic Research.

Moxnes, A. (2010). Are sunk costs in exporting country specific? Canadian Journal of Economics, 43(2), 467-493.

Ottaviano, G., \& Thisse, J. F. (1999). Monopolistic competition, multiproduct firms and optimum product diversity. (Discussion Papers 2151). CEPR. https://ideas.repec.org/p/cpr/ceprdp/2151.html. Accessed 1 June 2019.

Serti, F., Tomasi, C., \& Zanfei, A. (2010). Who trades with whom? Exploring the links between firms' international activities, skills, and wages. Review of International Economics, 18(5), 951-971.

Stock, J., \& Yogo, M. (2005). Testing for weak instruments in linear IV regression. In J. H. Stock \& D. W. K. Andrews (Eds.), Identification and inference for econometric models: Essays in honor of Thomas $J$ Rothenberg. New York: Cambridge University Press.

Verhoogen, E. A. (2008). Trade, quality upgrading, and wage inequality in the Mexican manufacturing sector. The Quarterly Journal of Economics, 123, 489-530.

Wagner, J. (2012). German multiple-product, multiple-destination exporters: Bernard-Redding-Schott under test. Economics Bulletin, 32(2), 1708-1714. 
Yeaple, S. R. (2005). A simple model of firm heterogeneity. Journal of International Economics, 65, 1-20.

Publisher's Note Springer Nature remains neutral with regard to jurisdictional claims in published maps and institutional affiliations. 